\title{
АКТУАЛЬНЫЕ ПРОБЛЕМЫ ПРЕДУПРЕЖДЕНИЯ ТЕРРОРИСТИЧЕСКИХ ПРЕСТУПЛЕНИЙ, СОВЕРШАЕМЫХ НА ТРАНСПОРТЕ
}

\section{ACTUAL PROBLEMS OF PREVENTION OF TERRORIST CRIMES COMMITTED ON TRANSPORT}

Yu. Dobrovolskaya

P. Agapov

Summary. Since the beginning of the 2000s, terrorist acts committed on transport, which resulted in numerous human casualties, have been regularly included in the official statistics of the Russian Federation. The leadership of our country did not immediately come to understand that it is easier and cheaper to prevent terrorist attacks than to eliminate their consequences. To date, Russia has managed to form an effective system for preventing terrorist crimes related to the transport sector, and to reduce them to a minimum. However, this does not indicate the complete elimination of threats. The activities of terrorist groups are constantly being improved, therefore, in parallel with this process, work should be developed to further implement the most effective measures to prevent such socially dangerous crimes as terrorist attacks.

Keywords: explosive device, warning, terrorism, terrorist crime, transport.

\author{
Добровольская Юлия Сергеевна \\ Аспирант, Российский Университет Транспорта \\ (МИИТ) \\ yul1556911@yandex.ru \\ Агапов Павел Валерьевич \\ Д.ю.н., профессор, Российский Университет \\ Транспорта (МИИТ)
}

Аннотация. С начала 2000-х гг. террористические акты, совершенные на транспорте, повлекшие за собой многочисленные человеческие жертвы, стали регулярно попадать в данные официальной статистики РФ. Руководство нашей страны не сразу пришло к пониманию, что теракты легче и дешевле предупреждать, нежели устранять их последствия. К настоящему времени в России удалось сформировать действенную систему предупреждения террористических преступлений, связанных с транспортной сферой, свести их к минимуму. Однако, это не свидетельствует о полном устранении угр0з. Деятельность террористических группировок постоянно совершенствуется, следовательно, параллельно этому процессу должна развиваться работа по дальнейшему внедрению наиболее эффективных мер предупреждения столь общественно опасных преступлений, как теракты.

Ключевые слова: взрывное устройство, предупреждение, терроризм, террористическое преступление, транспорт.
$\mathbf{T}$ ранспортная система считается одной из наиболее уязвимых сфер к преступным проявлениям. Примечательно, что в ежемесячных аналитических отчетах ГИАЦ МВД России состояние преступности на транспорте описывается в отдельном разделе. Если изучить данные за последние три года, то можно увидеть, что общее число зарегистрированных преступлений, совершенных на транспорте, является достаточно стабильным показателем, составляющим в среднем около 35 тыс. единиц, или около 1,5\% от всего количества преступлений (38 605 случаев в 2018 г., $36153-$ в 2019 г., 33527 - в 2020 г.) [18; 19; 20].

Актуальность обеспечения безопасности транспортной системы происходит из того, что в отсутствие транспортных сообщений жизнедеятельность современного общества является невозможной, она полностью заблокируется. Огромная по площади территория России подразумевает ежедневное перемещение миллионов граждан и миллионов тонн грузов автомобильным, железнодорожным, воздушным и иными видами транспорта. Учитывая это, объекты транспортной инфраструктуры входят в круг интересов преступных групп, в том числе, террористических [6, с. 49]. В многочисленных исследованиях, посвященных данному вопросу, отмечается, что примерно 70\% террористических актов связано с транспортной системой, как объектом атаки (вокзалы, аэропорты, дороги), или с самими транспортными средствами, как орудиями атаки (в первую очередь, это самолеты), в совокупности обеспечивающими мощное поражающее воздействие и широкий общественный резонанс [10]. Что, в полной мере, соответствует ключевой цели идеологии терроризма - управление социумом путем превентивного устрашения [16, с. 151]. При этом, как справедливо подмечено Е.Н. Савинковой, терроризм на транспорте, с одной стороны, относится к традиционной общеуголовной преступности, а, с другой стороны, имеется 
у него и специфический признак - организация преднамеренных преступных действий в местах массового скопления лиц, вызов наибольшей паники и беспорядков, усложнение противодействия со стороны властей и т.д. Так террористы достигают свою субъективную цель - использовать «общество» в качестве необходимого «передаточного» звена между ними и адресатами требований (чаще всего конкретное государство, его руководство) [17, с. 36].

Самый крупный по числу жертв теракт в мировой истории произошел в США 11 сентября 2001 г. Согласно официальным сведениям, его жертвами стали 2996 человек. Атака как раз была совершена посредством транспортных средств - 4-х захваченных с пассажирами на борту самолетов (два из них врезались в башни-близнецы в Нью-Йорке, третий - в здание Пентагона в Вашингтоне, четвертый рухнул около Питтсбурга) [4]. Именно с 11 сентября 2001 г. ведет свой отчет международная (глобальная) стратегия противодействия терроризму, поддержанная большинством государств. Тогда же они начали предпринимать беспрецедентные усилия по обеспечению правопорядка и безопасности на многих объектах транспортной инфраструктуры. Особенному переоснащению, в том числе, и в Российской Федерации, подверглись международные аэропорты и авиалайнеры. Были внедрены: новые средства досмотра багажа, технологии тестирования пассажиров, специальные программы обучения персонала и др.

Однако, эти меры не позволили предотвратить, в частности, трагедию, произошедшую 24 августа 2004 г., когда почти одномоментно (интервал был равен одной минуте) произошли взрывы двух находящихся в воздушном пространстве самолетов: ТУ-134А-3 (компания «Волга-Авиаэкспресс») и ТУ-154Б-2 (компания «Сибирь»). Оба авиалайнера вылетели из аэропорта Домодедово (г. Москва), конечным пунктом первого был г. Волгоград, а второго - г. Сочи. Жертвами стали все пассажиры и члены экипажей - всего 90 человек (44 и 46 соответственно). Причиной крушения стало взрывчатое вещество, пронесенное на борты террористками-смертницами А. Нагаевой и С.Джебирхановой. Впоследствии следственными органами была установлена информация о том, что указанных женщин задерживали, но потом отпустили, кроме того, билеты они приобрели у «спекулянта» при участии представителя одной из авиакомпаний.

После этого последовали события, связанные со взрывами: в московском метрополитене на станциях «Парк культуры» и «Лубянка» (29 марта 2010 г., число погибших - 39 чел. и 33 чел. раненных), поезда «Невский экспресс» (27 ноября 2009 г., число погиб- ших - 28 чел. и 95 чел. раненных), в здании аэропорта Домодедово (24 января 2011 г., число погибших - 35 чел. и 180 чел. раненных), на входе в железнодорожный вокзал «Волгоград |» (29 декабря 2013 г., число погибших - 18 чел. и 45 чел. раненных) и в волгоградском же троллейбусе (30 декабря 2013 г., число погибших - 16 чел. и 25 чел. раненных) и др. [11]. При этом, считается, что самый страшный теракт в истории России (включая и советский период), связанный с транспортной сферой,- это крушение самолета Airbus A-321 (компания «Когалымавиа») 31 октября 2015 г. При выполнении рейса «Шарм-аль-Шейх - Санкт-Петербург» на борту произошел взрыв, унесший в итоги жизни 224 чел. (217 пассажиров и 7 членов экипажа). Проведя исследование обломков лайнера, эксперты установили причину трагедии - детонирование взрывного устройства иностранного происхождения, что позволило рассматривать ее в качестве террористического акта [13, с. 52]. В последующем были также получены данные о размещении устройства в багажном отсеке хвостовой части самолета, попавшего туда под видом багажа при содействии сотрудника сервисной службы международного аэропорта «Шарм-Эш-Шейх». Однако, по сегодняшний день ни одно лицо, виновное в теракте, не установлено и не привлечено к ответственности [7].

Вообще, не может не ужасать статистика раскрываемости преступлений, именуемых иначе, как «транспортный терроризм». В отдельных работах приводятся данные о 15-20\% от общего числа случаев [17, с. 36]. Но, учитывая, что именно такие дела вызывают наибольший резонанс, государство не может не давать на них соответствующую реакцию.

Начало 2000-х гг. ознаменовалось активизацией работы российских властей над антитеррористическим законодательством. Значимой вехой стало подписание и вступление в силу Федерального закона от 6 марта 2006 г. № 35-Ф3 «О противодействии терроризму» [2], позволившего установить единые ключевые принципы противодействия терроризму, правовые и организационные основы профилактики терроризма и борьбы с ним, минимизации и (или) ликвидации последствий проявлений терроризма, а также порядок применения в этой деятельности сил и средств силовых структур. По мнению ряда экспертов, утверждение названного Федерального закона инспирировало существенную модернизацию норм и в иных отраслях законодательства [8, с. 14]. В качестве примера можно привести принятый годом позже Федеральный закон от 9 февраля 2007 г. № 16-Ф3 «О транспортной безопасности» [1], уделивший особое внимание вопросам защищенности объектов транспортной инфраструктуры и транспортных средств от противоправных деяний, в том числе, террористического характера. Указанный норматив- 
но-правовой акт закрепил, что для обеспечения транспортной безопасности необходимо: категорировать объекты транспортной инфраструктуры и транспортных средств; по отдельности оценивать их уязвимость; разрабатывать и реализовывать соответствующие планы защиты; осуществлять контроль и надзор в сфере транспортной безопасности. В последующем многие из названных требований получили свою конкретизацию в Указе Президента РФ от 31 марта 2010 г. № 403 «О создании комплексной системы обеспечения безопасности населения на транспорте» [3].

Стоит сказать, что следствием каждого нового факта террористического преступления на транспорте было усиление антитеррористических мер. Совершенствовалась система обеспечения безопасности всего транспортного комплекса, расширялись полномочия правоохранительных органов, а также повышалась их технологическая оснащенность, внедрялись в практику новые способы и формы осуществления оперативно-розыскных мероприятий. Причем, в эту работу были активно включены не только государственные ресурсы, но и частные - в лице хозяйствующих субъектов, занятых в сфере транспорта [5, с. 3]. Постепенно пришло осознание, что с террористами не надо бороться, надо предупреждать любые попытки совершения ими преступных деяний. Стало важно именно то понимание, которое заложено криминологической наукой в понятие «предупреждение». «Предупредить» значит «заранее принятыми мерами устранить то, что угрожает» $[12$, c. 62].

Справедливым видится утверждение, что в итоге в Российской Федерации удалось сформировать целостный механизм предупреждения террористических преступлений, в том числе, совершаемых на транспорте. Она включила в себя: 1) организацию единой государственной системы предупреждения терроризма, ключевую роль в которой играют Национальный антитеррористический комитет и Федеральный оперативный штаб; 2) развитие нормативно-правовой основы в сфере антитеррористической защищенности объектов транспортной инфраструктуры и транспортных средств; 3) повышение государственного контроля (надзора) за обеспечением транспортной безопасности; 4) усиление охраны и внедрение инновационных технологий в структуру технической оснащенности метро, аэропортов, вокзалов и др. критически важных объектов; 5) разработку специальных программ по обучению, аттестации, тестированию и пр. руководящего состава, сотрудников служб безопасности и иного персонала транспортной отрасли; 6) проведение активной предупредительно-профилактической работы среди населения; 7) стабилизацию ситуации на Северном Кавказе и других конфликтогенных регионах; и др.
22 сентября 2020 г. Д.А. Медведев, занимающий пост заместителя председателя Совета безопасности РФ, озвучил данные о полном ограждении российского транспортного комплекса от посягательств террористов в последние два года (речь шла о 2018 и 2019 гг.). Им было особо отмечено, что в течение 2019 г. силовые структуры смогли предотвратить 34 террористических акта на транспорте, при том, что за неполный 2020 г. в статистику попали 24 незаконных вмешательства в работу транспортных объектов и 517 угроз такого рода вмешательства [14].

Вместе с тем, складывающаяся сегодня картина в части реальной минимизации террористических угроз в транспортной сфере не должна приводить к успокоению, напротив, реализация антитеррористических мер предупредительного характера должна продолжаться и даже усиливаться. Тем более в условиях, когда в научных и экспертных кругах все «громче» звучат разговоры о том, что террористические группировки не стоят на месте, они постоянно совершенствуют свой преступный потенциал, привлекая в свои ряды высококлассных специалистов - программистов, инженеров, психологов и др. Абсолютно верно высказывание П.Н. Кобеца о том, что, невзирая на существенное усиление, а иногда и полный пересмотр мероприятий обеспечения безопасности в большинстве аэропортов мира, наблюдаемые к концу второго десятилетия XXI в., не вызывает сомнения, что изобретательность террористов может позволить придумать им многочисленные способы по обходу действующих процедур [9, с. 54]. А.В. Михайлов в свой статье приводит в пример материалы, опубликованные авторитетным британским изданием «The Sandy Times». Журналисты утверждают, что в структуре ультрарадикальной международной террористической организации «Аль-Каида» (запрещзенная в РФ террористическая организация) при помощи сотрудничающих с ней хирургов удалось создать «человека-бомбу». Речь идет о вживлении в тело человека (в бедра и грудь) специальных имплантатов, способных взорваться (катализатором взрыва становится введение имплантат посредством шприца особой жидкости). Основная цель разработки таких имплантатов - незаметный пронос взрывчатых веществ в самолет. Ни один из применяемых сегодня службами безопасности аэропортов, оснащенных по последнему слову техники, сканеров такие вещества обнаружить не может [15, с. 31].

В контексте сказанного, уместно предположить, что ни государственные программы, ни совершенные технические устройства не могут снизить важность человеческого фактора. Наглядное подтверждение этому теракт 24 августа 2004 г., унесший жизни 90 человек. Предотвратить возможность совершения террористи- 
ческих преступлений на транспорте, спасти от гибели или причинения увечий многих граждан в большей степени может (и должно) полноценное исполнение своих полномочий сотрудниками правоохранительных органов и служб безопасности, участвующих в охране объектов воздушного, железнодорожного, водного, автомобильного и иного транспорта. А это требует долгосрочного специального обучения персонала и дальнейшего совершенствования программ служебной подготовки. Немаловажным здесь является обращение к позитивному опыту зарубежных государств. П.Н. Кобец приводит в пример эффективные разработки национальных авиалиний Израиля. Данное государство, столкнувшееся с проблемой угонов самолетов и терактов еще в 1970-е гг., смогло выстроить собственную, во многом, уникальную систему обеспечения безопасности, как пассажиров, так и персонала. Как следует из практики израильских спецслужб, при появлении экстренной информации о подготавливаемом террористическом акте, каждый сотрудник аэропорта, даже самый последний в цепочке, оперативно получает весь объем необходимых сведений, поскольку именно он может столкнуться с потенциальным террористом [9, c. 56].

Не принижая значимость и отечественного опыта, следует подчеркнуть, что в понимании сотрудников правоохранительных органов и служб безопасности объектов транспортной инфраструктуры должно укорениться понимание того, что наряду с совершенствованием предпринимаемых ими мер, происходит совершенствование деятельности террористических организаций, появление в их арсенале новых способов совершения терактов. Следовательно, важно не стоять на месте, думая, что предпринимаемые меры по обеспечению транспортной безопасности и так являются безупречными. Только постоянная модернизация системы подготовки и обучения лиц, задействованных в охране транспорта, которая будет базироваться на наиболее перспективных современных исследованиях и методиках, позволит поддерживать в стабильном, безопасном состоянии весь транспортный комплекс РФ, а, самое главное, сохранять человеческие жизни.

\section{ЛИТЕРАТУРА}

1. Федеральный закон от 09.02.2007 № 16-Ф3 «0 транспортной безопасности» (ред. от 02.12.2019) // СЗ РФ. 2007. № 7. Ст. 837; 2019. № 49 (ч. 4). Ст. 6974.

2. Федеральный закон от 06.03.2006 № 35-Ф3 «0 противодействии терроризму» (ред. от 08.12.2020) // СЗ РФ. 2006. № 11. Ст. 1146; 2020. № 50 (ч. 3). Ст. 8074.

3. Указ Президента РФ от 31.03.2010 № 403 «0 создании комплексной системы обеспечения безопасности населения на транспорте» // СЗ РФ. 2010. № 14. Ст. 1637.

4. Десять крупнейших терактов в мире [Электронный ресурс] // ТАСС. 14.11.2015. Режим доступа: https://tass.ru/mezhdunarodnaya-panorama/2436364 (дата обращения: 25.05.2021).

5. Дмитриев С.Н. Новации в законодательстве о транспортной безопасности // Транспортное право. 2014. № 4. С. 3.

6. Занина Т.М., Агаркова Н.А. Взаимодействие правоохранительных органов по обеспечению общественного порядка и безопасности на объектах транспортной инфраструктуры // Административное право и процесс. 2020. № 12. С. 49.

7. Званцев В. «Мы не хотели их отпускать»: кто виновен в авиакатастрофе над Синаем [Электронный ресурс] // РИА Новости. 31.10.2020. Режим доступа: https://ria.ru/20201031/avikatastrofa-1582326092.html (дата обращения: 25.05.2021).

8. Качалов В.В., Жилкин М.Г., Маслакова Е.А. Некоторые направления совершенствования правового обеспечения антитеррористической безопасности // Военно-юридический журнал. 2015. № 1. С. 14.

9. Кобец П.Н. Противодействие терроризму в авиационной сфере: положительный опыт и проблемы // Российский следователь. 2018. № 9. С. 54, 56.

10. Конюхова А.С. Терроризм и безопасность на транспорте: Итоги 20-й Международной научно-практической конференции (г. Москва, 9-10 февраля 2021 г.) [Электронный ресурс] // Право и авиация. 07.03.2021. Режим доступа: https://avialaw.blog/blog/obzory-meropriyatiy/20-ya-mezhdunarodnayanauchno-prakticheskaya-konferenciya-terrorizm-i (дата обращения: 25.05.2021).

11. Крупные теракты на транспорте в России в 2009-2017 годах [Электронный ресурс] // РИА Новости. 03.04.2017. Режим доступа: https://ria. ru/20170403/1491367151.html (дата обращения: 25.05.2021).

12. Кузнецов А.П. Криминалистические меры по предотвращению террористических проявлений на объектах транспортной инфраструктуры // Российская юстиция. 2015. № 7. С. 62.

13. Макаров А.В., Чумаченко М.В. Терроризм и экстремизм: современное понимание и актуальные проблемы // Юридический мир. 2016. № 2. С. 52.

14. Медведев сообщил, что на транспорте в России предотвращено несколько десятков терактов [Электронный ресурс] // ТАСС. 22.09.2020. Режим доступа: https://tass.ru/politika/9519507 (дата обращения: 25.05.2021).

15. Михайлов А.В. Необходимость наращивания технических средств противодействия терроризму на объектах транспортной инфраструктуры // Транспортное право. 2013. № 2. С. 31.

16. Одесский М., Фельдман Д. Террор как идеологема (к истории развития) // Общественные науки и современность. 1994. № 6. С. 151.

17. Савинкова Е.Н. Особенности преступности террористической направленности на транспорте // Транспортное право. 2012. № 3. С. 36. 
18. Состояние преступности в России (за январь-декабрь 2018 г.) [Электронный ресурс] // Официальный интернет портал МВД России. 18.01.2019. Режим доступа: https://xn — b1aew.xn — p1ai/reports/item/16053092/ (дата обращения: 25.05.2021).

19. Состояние преступности в России (за январь-декабрь 2019 г.) [Электронный ресурс] // Официальный интернет портал МВД России. 24.01.2020. Режим доступа: https://xn — b1aew.xn — p1ai/reports/item/19412450/ (дата обращения: 25.05.2021).

20. Состояние преступности в России (за январь-декабрь 2020 г.) [Электронный ресурс] // Официальный интернет портал МВД России. 21.01.2021. Режим доступа: https://xn — b1aew.xn — p1ai/reports/item/22678184/ (дата обращения: 25.05.2021).

( ) Добровольская Юлия Сергеевна ( yul1556911@yandex.ru ), Агапов Павел Валерьевич.

Журнал «Современная наука: актуальные проблемы теории и практики»

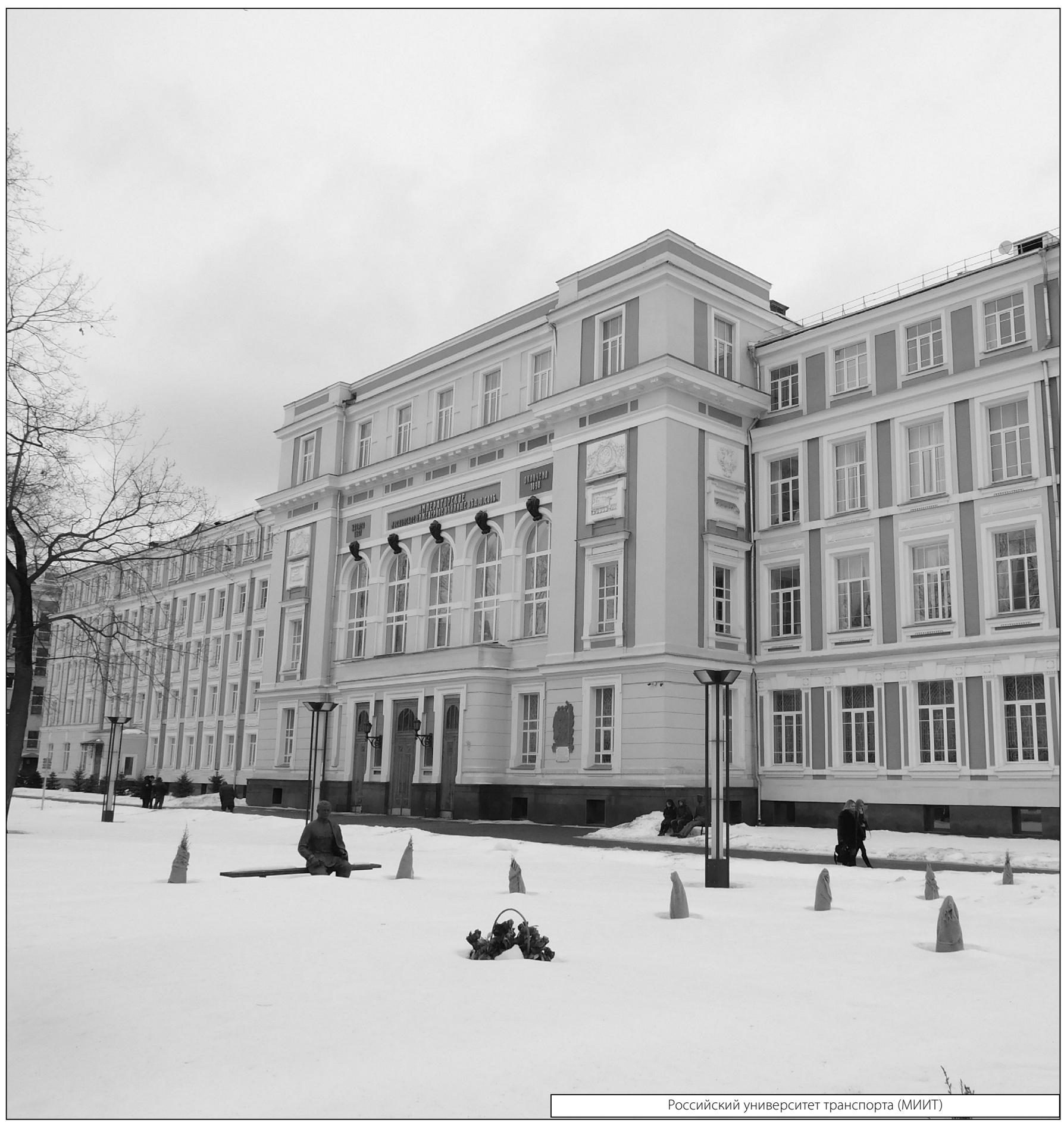

